\title{
The Deactivation of Implantable Cardioverter-Defibrillators
}

\author{
Medical, Ethical, Practical, and Legal Considerations
}

Jörg Carlsson, Norbert W. Paul, Matthias Dann, Jörg Neuzner, Dietrich Pfeiffer

\section{SUMMARY}

Background: Implantable cardioverter-defibrillators (ICDs) cannot prevent death from progressive heart failure or non-cardiac disease. Patients with ICDs may receive defibrillation therapy from their devices in the last days of their lives, when such therapy does not accord with the goal of palliative treatment, but rather lowers these patients' quality of life and compromises their dignity.

Methods: We present a case report and a selective review of pertinent literature retrieved by a PubMed search, including two up-to-date consensus documents.

Results: One-third to two-thirds of all ICD patients receive defibrillation therapy in the final days of their lives. Patients and their physicians rarely discuss deactivating the ICD. The ethical aspects of such decisions need to be considered. As a practical matter, it is possible to deactivate certain types of electrotherapy selectively, while leaving others active. There are logistical considerations as well.

Conclusion: Automatic defibrillation therapy in a terminally ill patient with an ICD is painful and distressing, serves no medical purpose, and should be avoided. This issue should be discussed with ICD patients and their families. Institutions caring for terminally ill patients, as well as cardiology units where ICD patients are treated, should develop ethically and legally well-founded protocols for dealing with the question of ICD deactivation.

\section{- Cite this as:}

Carlsson J, Paul NW, Dann M, Neuzner J, Pfeiffer D:

The deactivation of implantable cardioverter-defibrillators:

medical, ethical, practical, and legal considerations. Dtsch Arztebl Int 2012; 109(33-34): 535-41. DOI: 10.3238/arztebl.2012.0535

Department of Internal Medicine, Section of Cardiology, Kalmar County Hospital: Prof. Dr. med. Carlsson Institute for the History, Philosophy and Ethics of Medicine, University Medical Center of the Johannes Gutenberg University Mainz: Prof. Dr. rer. medic. Paul

Düsseldorf: Dr. jur. Dann

Department of Cardiology and Intensive Care, Klinikum Kassel: Prof. Dr. med. Neuzner

Divison of Cardiology and Angiology, Department of Internal Medicine, Neurology und Dermatology, University Hospital Leipzig AöR: Prof. Dr. med. Pfeiffer rophylactic treatment using an implantable cardioverter-defibrillator (ICD) is indicated for patients with an increased risk of sudden cardiac death but an otherwise good prognosis $(1,2, \mathrm{e} 1)$. Germany leads Europe in this area, with more than 300 ICDs fitted per million inhabitants per year (3). Approximately one-third of patients newly fitted with ICDs in Western countries are 70 or more years old (4). While an implantable cardioverter-defibrillator (ICD) does effectively reduce the risk of sudden cardiac death, it cannot prevent death from heart failure or noncardiac diseases.

When a patient with an implantable defibrillator approaches the end of his/her life, whether as a result of treatment-refractory heart failure or due to a noncardiac disease, discussion of the end of ICD treatment may be indicated. Shock therapy at the end of life has no medical benefit and may cause significant stress for the patient, his/her relatives, and nursing staff. Side effects associated with shocks, sometimes occurring simultaneously (including transient loss of consciousness, uncontrolled defecation, enuresis, nausea, and vomiting) can have an adverse effect on the patient's dignity (5, e2).

This article begins with a case study and describes these issues on the basis of the results of a search of the literature. In 2010 two consensus documents, one European (6) and one from the USA (7), were published on the subject of pacemaker and defibrillator deactivation. The medical and ethical problems discussed are not confined to ICD treatment; rather, medical and technical developments have also resulted in similar conflicts in other areas of medicine, such as treatment with implantable left ventricular assist devices (e3).

\section{Methods}

This article follows international guidelines $(6,7)$ and is based on a selective search of the literature using the database PubMed (www.ncbi.nlm.nih.gov), which found 75 articles using the keywords "ICD deactivation" and "defibrillator deactivation." A case study should serve as an introduction for readers who are not cardiac specialists. Legal aspects are also included in this review article. 


\section{Case study}

In June 2009 a 67-year-old man was fitted with a defibrillator when a biventricular pacemaker was implanted (cardiac resynchronization therapy, or CRT-D) (see Glossary). He was suffering from NYHA Class II-III heart failure caused by nonischemic cardiomyopathy. His left ventricular function was considerably compromised, with an ejection fraction of $25 \%$ to $30 \%$, and he had a complete left bundle branch block. Despite anticongestive drug treatment and technically functional biventricular stimulation, his heart failure continued to worsen. Six months after implantation it was recognized that the patient belonged to the small group of nonresponders, i.e. patients who are not helped by CRT $(8,9)$. The next treatment option selected was palliative treatment involving care at home in communication with the hospital. Despite good home care, during the winter of 2009/2010 the patient had to be admitted to the hospital several times. Each time he was cared for in a palliative care unit, where he was treated for anxiety attacks (caused by paroxysmal dyspnea) in particular. At this time his heart failure was described as NYHA Class III-IV. In early February he was readmitted to the palliative care unit and a decision was made to end drug-based treatment for his heart failure. He now received only palliative treatment. At the same time, morphine treatment was begun. In October 2009 his treating physician had already recorded in his electronic medical records that the patient should not be resuscitated in the event of cardiac arrest. In conversation with the palliative care physician, the patient himself now reported a feeling of security, which in his opinion was connected with the ICD. The physician observed at this time that the existence of the defibrillator represented an "ethical dilemma." On the day before the patient's death in February 2010 the cardiology hospital was consulted, with the request to deactivate the ICD, because the patient had received shock therapy induced by the device several times in a short period. In the opinion of both the patient's wife and the nursing staff who were present, the shocks were considerably stressful. At this point the patient was somnolent and moribund. The staff recorded in the patient's electronic medical records that ICD treatment had been "unethical" and had disrupted the patient's dignified, peaceful death. The patient died the day after his ICD had been deactivated.

\section{Medical issues}

One medical aspect of this case which may seem trivial but is worth mentioning from the outset is that all patients, including those with an ICD will die eventually. The annual mortality rate of patients with ICDs varies depending on the underlying disease. In one US registry study, it was between $11.3 \%$ and $16.8 \%$ (8). Most ICD patients die of heart failure. Noncardiac causes of death such as cancer do, however, occur. A patient with an ICD may die just a few months after the defibrillator is implanted, but may live for more than 20 years, with several changes of device. Relevant medical guidelines state that ICD implantation is only indicated if the patient has a good prognosis when the ICD is fitted, apart from the risk of sudden cardiac death, and that his/her statistical life expectancy is at least one year (2). As the case study illustrates, it is impossible to determine a patient's prognosis reliably, partly because of the epistemological status of prognosis (10). Uncertainty of prognosis is a particular problem when a patient with severe or very severe heart failure (NYHA Class III-IV) is fitted with a combined pacemaker for biventricular stimulation and defibrillation (a CRT defibrillator) and continues to deteriorate, i.e. is a nonresponder (9), developing terminal, treatment-refractory pump weakness.

By no means do all ICD patients receive shock therapy despite active treatment functions while moribund, because ventricular arrhythmia does not necessarily occur while patients are moribund. In a summary of deceased ICD patients, it was found that 15 of 55 (27\%) had received appropriate shock therapy in the last phase of their lives, one further patient $(2 \%)$ had received inappropriate shocks, and for the remaining 39 of the 55 patients $(71 \%)$ neither ventricular arrhythmia nor shock therapy was recorded (Goldenberg I, Moss AJ, McNitt S, Zareba W, Andrews ML: Defibrillator discharge at the time of terminal events in Madit-II. HRS annual meeting 2007, abstract AB 14-6, www.abstracts2view. com/ hrs/view.php?nu=HRS7L_20075088). If an ICD also acts in the event of non-life-threatening tachycardia, e.g. with high ventricular rate as a result of atrial fibrillation, treatment is described as inadequate. If appropriate shocks are given as a result of ventricular tachycardia or ventricular fibrillation, the ICD has provided appropriate treatment. A further study from US hospices reports that $64 \%$ of ICD patients received shock therapy during the last phase of their lives, or even after death (5).

\section{Medical ethics}

It might initially be assumed that an ICD or pacemaker is no different from other hi-tech medical treatments or aids in terms of the ethical discussion surrounding their deactivation. Respect for patients' self-determination, which is becoming more and more strongly enshrined in law (e.g. in Germany with the 2009 act that introduced the third change to the law on care), includes a patient's right to refuse treatment (Box). If a patient dies after the end of a treatment that is no longer indicated, death is considered to be the result of the underlying disease and not of treatment provided by the physician. The increasingly common argument that deactivating a hi-tech medical aid is "passive assistance in dying," or even that switching off a device is "active assistance in dying" because of the nature of treatment, is ethically incorrect in the precisely defined situation described above. Physicians' and patients' assessments of active and passive treatments are often dominated by great uncertainty. This can lead to disputes in determining the aim of treatment, though ethically such controversy is often unfounded (11-15, e4-e8). In daily clinical 


\section{Selected legal issues}

So far as can be ascertained, there have been no court decisions to date that have dealt specifically with the deactivation of an implantable cardioverter-defibrillator (ICD) from the point of view of criminal law. What follows should therefore be interpreted as the authors' own judgments and assessments based on (German) criminal law. They are based partly on high court rulings in comparable cases.

ICD deactivation by a physician as part of medical treatment is a form of "discontinuation of treatment" to be judged according to criminal law if it causes the death of the patient. Such discontinuation of treatment is only permissible if it is in line with the patient's wishes. Germany's Federal Court of Justice confirmed this in a 2010 landmark ruling (e18). The cornerstone of assessment according to criminal law in such cases is the question of whether the patient has truly given consent. There are various types of consent. The strongest, and for physicians the safest, form is specific consent given by a patient who has the capacity to decide for himself/herself that the ICD should be deactivated. Such consent assumes the following:

- The patient must have the capacity to give consent.

- The decision must be free of any defects. This requires the provision of appropriate medical information to enable the patient to fully understand the consequences of his/her decision.

- Consent must be expressed explicitly or implicitly and must cover deactivation of the ICD in a particular situation.

- Applying the standards of a new ruling by the German Federal Court of Justice, deactivation of the ICD must aim to "result in or restore a condition that allows a disease already present to take its course, whereby although suffering may be alleviated the disease is not or is no longer treated, leading ultimately to the patient being allowed to die." Only if this requirement is met can consent be used to justify ICD deactivation (compare Federal Court of Justice, Ruling of June 25, 2010, 2 Criminal Verdict 454/09).

- Consent must be expressed before the ICD is deactivated.

As a safeguard and to provide proof of consent, it should be documented that the patient was informed and subsequently gave consent for discontinuation of treatment.

If the patient is unconscious or unable to respond for a long period of time, it must be verified whether the patient has a living will that covers ICD deactivation (cf. §§1901a et seq., German Civil Code). If the patient does not have a living will or if his/ her living will does not cover the current status of the patient's life and treatment, the presumed wishes of the patient must be established (\$1901a II, German Civil Code). The procedure for deciding whether a patient's living will covers ICD deactivation and establishing the patient's presumed wishes must follow $\S \S 1901 \mathrm{a}$ et seq. of the German Civil Code, in order to avoid the risk of criminal prosecution. This requires, for example, discussion of the medically indicated interventions between physician and carer/authorized representative, taking into account the patient's wishes established beforehand ( $\$ 1901 \mathrm{~b}$, German Civil Code).

In the authors' opinion, there can be no question of unilateral ICD deactivation that leads to death and is not based on the patient's wishes. If a patient who still has the capacity to make decisions and has been appropriately informed wishes for his/ her ICD to remain activated, this wish must be respected even if it is medically questionable. In light of the individual's right to self-determination and physical integrity, there is a difference between ICD deactivation that is unwanted by a patient and administration of treatment that can have no medical benefit, to which the patient is not entitled.

In brief, it is recommended that ICD deactivation that would lead to death should be guided by legal advice, as it may give rise to detailed questions that are difficult to answer and cannot be discussed comprehensively here.

practice, for example, the end of mechanical ventilation or dialysis treatment is a subject of ethical discussion. Numerous studies show that it is not unusual for physicians and lawyers to differ from each other in where they define the boundary between ending lifesustaining treatment, which is permitted, and euthanasia or even assisted suicide, which are not permitted (11-15, e9-e14). Implanted defibrillators and pacemakers are different from other hi-tech medical aids such as ventilation or dialysis machines because they are implanted into the patient's body. The term "integral device" (11) was introduced to describe these devices, though naturally this did not lead to any automatic improvement in the clarity of ethical discussions.
Thus, in medical ethics literature it is often asked what distinguishes an external ventilation machine, implanted pacemaker, or ICD from a transplanted heart. The terms "replacement therapy" and "substitutive therapy" were introduced into the literature in order to provide more precise definitions (12). If an item functions as part of the body and completely replaces a physiological function, it can be described as "replacement therapy." This means that a transplanted heart or a transplanted kidney is replacement therapy, whereas the use of a ventilation machine must be classified as "substitutive therapy." Different rules apply to ending these two types of therapy. Nobody would describe the "deactivation" of a transplanted heart via 


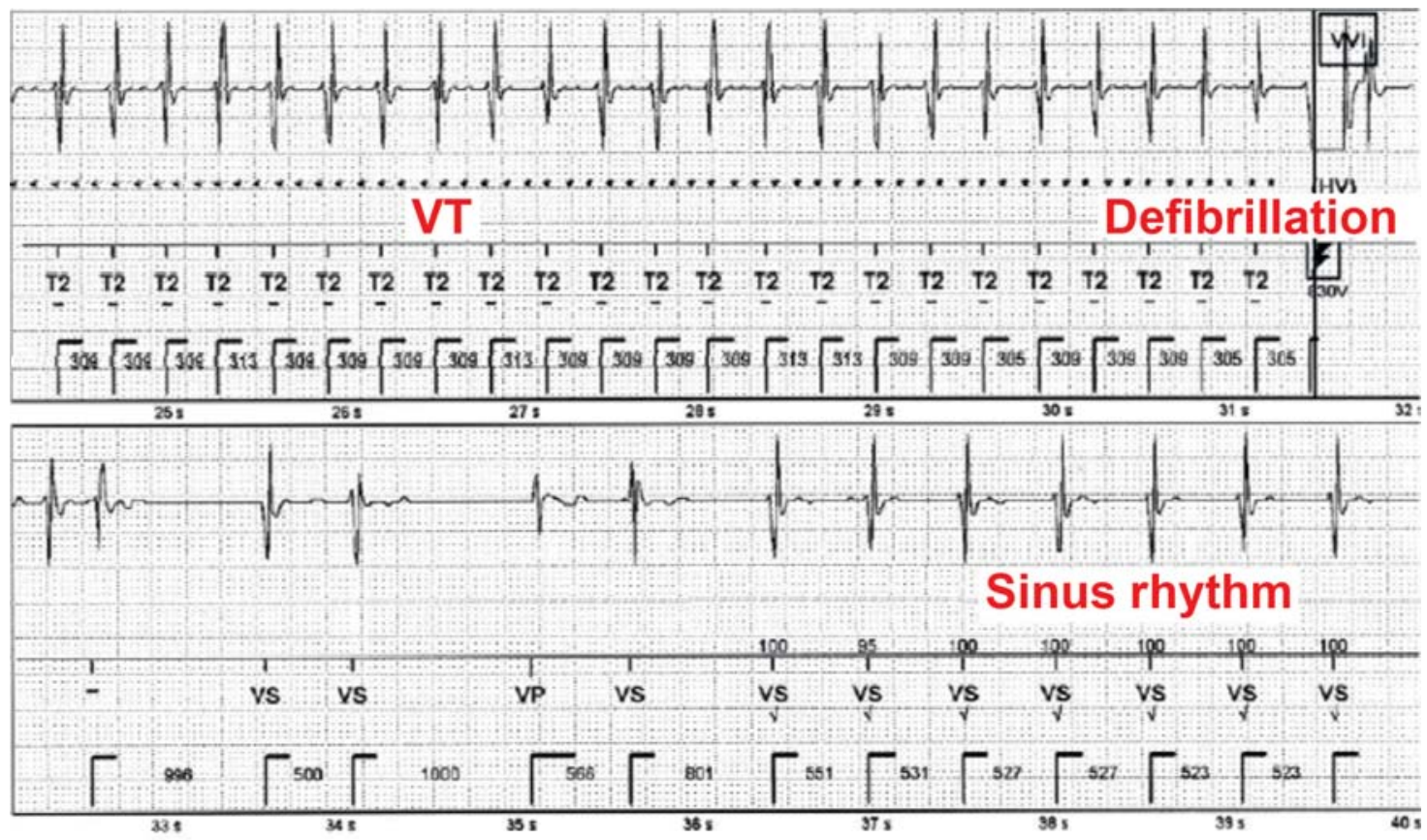

Figure: Extract from an ICD readout, showing ventricular tachycardia (VT) with a cycle length of 310 ms (heart rate 194 bpm). Several attempts to resolve this using antitachycardia pacing have failed (not shown); defibrillation resolves the tachycardia. After several slow cycles, there is a regular sinus rhythm with a cycle length of $525 \mathrm{~ms}$ (heart rate $114 \mathrm{bpm}$ )

intravenous administration of a fatal dose of potassium as anything other than active killing, whereas switching off a ventilation machine or ending dialysis treatment must be regarded as medically and ethically justifiable in certain cases. An item classified as substitutive therapy has not become part of the patient's body; this excludes integrated devices like pacemakers or ICDs. Discussion is still ongoing as to how pacemakers and defibrillators should be classified: as replacement therapy or substitutive therapy $(11,12)$. However, there does seem to be extensive agreement that the deactivation of a pacemaker in a pacemaker-dependent patient is fundamentally different from the deactivation of the antitachycardia functions of an $\operatorname{ICD}(6,7,13-15)$. In the former case, the intervention leads to the patient's death within a short time, while in the latter only a risk-reducing treatment is deactivated (14). The differences between the two interventions described above, from the point of view of medical ethics, are questioned by some authors, who state that only the patient's wishes should be the basis for this kind of ethical judgment, not an artificial difference between forms of treatment (14). However, this point of view overlooks the objections to an idealized concept of patient autonomy that have recently been discussed at length. These objections concern the fact that the concept of autonomous patient wishes is based on an ideal of rational decision-making that has never occurred in real life and is advocated from an individualistic point of view (in other words without sufficiently taking into account other persons who may be significant) and also disregards the fact that the person making the decision is dependent, when making decisions, on his/her body in a specific way (embodiment). Because a patient can come to feel that an ICD is a part of his/her body and so becomes part of his/her sense of self, the last point of this criticism is particularly relevant and should not be passed over. It is therefore also unsurprising if these authors consider the cause of the patient's death to be the underlying disease, e.g. third-degree AV block with no escape rhythm, rather than the deactivation of the pacemaker, for pacemaker-dependent patients. Deactivation of an "integral device" is not legally considered to be the cause of death (14).

There is usually more than one possible answer to these questions, which have been discussed only briefly here. Generally there are several possible answers, depending, in particular, on the socially and culturally contingent values of patients, doctors, and others involved in health care, and also on norms that have become law in various countries. The published guidelines therefore also stress that detailed, individual discussion with the patient must always take place and must be recorded before an ICD can be deactivated. The physician's freedom of conscience is also discussed: physicians may not want to deactivate an ICD, e.g. for religious reasons, but should refer a patient who wants his/her ICD to be deactivated to another physician $(6,7)$. A consensus document of this type, in Europe multinational (6) and in the USA covering several states (7), must be 
adapted to national and state behaviors and legal systems. However, regardless of national law, the deactivation of an ICD against the patient's will or against the will of the patient's representative or carer, or even unilateral (paternalistic) deactivation, may be ruled out $(6,7)$. In this context the boundary between a DNR (do not resuscitate) order in cases with no hope of recovery and the switching off of an ICD as a device integrated into the patient's body must be discussed $(6,7)$ : The decisive factor is that the patient is not entitled to demand an intervention that can have no medical benefit but is - according to prevailing opinion $(6,7)$ - entitled to refuse to allow his/her ICD to be deactivated.

Empirical ethical research shows that patients' and physicians' judgments do not always accord with the considerations of professional ethics (16-22, e15-e16). Patients also tend to overestimate the potential of an ICD in preventing death, so it is not uncommon for them to view consent for ICD deactivation as an act of suicide (20, e9). Most patients are hesitant to accept ICD deactivation, even when death from another cause is not far away (17). Physicians are equally disinclined to discuss this subject with their patients $(18, \mathrm{e} 17)$.

\section{Practical issues}

An ICD can provide both multiple kinds of antitachycardia treatment and antibradycardia stimulation (see Box, Glossary). Antitachycardia treatments that are automatically included are defibrillation (shock therapy) (see Figure) and antitachycardia pacing (ATP). The latter is not usually felt by the patient, whereas a defibrillation shock is both felt by patients and visible to others. The defibrillation function can be deactivated in isolation from the ATP function, which in rare cases (an estimated $2 \%$ to $4 \%$ ) can lead to an acceleration of ventricular tachycardia and even ventricular fibrillation. It is claimed that if the defibrillation function alone has been deactivated there is no longer any therapy available to treat this ventricular fibrillation, and the patient will die. Selective deactivation of the shock function can therefore cause the death of the patient in certain cases, if ATP causes an acceleration of tachyarrhythmia. On the other hand, deactivating both antitachycardia functions of an ICD, defibrillation and ATP, might cause progression of stable ventricular tachycardia that could easily be treated with ATP, leading to a drop in the patient's blood pressure. This would significantly decrease quality of life in the last days before the patient's death. The same is true of ending antibradycardia treatment in patients who are not pacemakerdependent. However, in those with a great need for pacing this would also substantially decrease quality of life, though it would not lead to death. Such practical medical matters, which go far beyond simple "on/off" considerations, must be taken into account. These detailed issues require not only technical knowledge of various manufacturers' ICDs and how to program them, but also knowledge of the patient's history of arrhythmia. It is also an advantage for the physician who deactivates the ICD to have known the patient for a

\section{GLOSSARY}

\section{ICD}

Implantable cardioverter-defibrillator. These defibrillators have various treatment modes. For antibradycardia they operate as pacemakers and provide stimulation when heart rate falls below the programmed heart rate. For ventricular tachycardia or ventricular fibrillation, ICDs can provide antitachycardia treatment such as defibrillation (shock therapy) and ATP (antitachycardia pacing). Internal defibrillation is very noticeable to patients unless they are unconscious as a result of arrhythmia, but they do not usually feel ATP.

\section{CRT}

Cardiac resynchronization therapy, a pacemaker with both right ventricle and left ventricle stimulation. This treatment option is primarily used for patients with heart failure and a left bundle branch block and is therefore sometimes called a heart failure or biventricular pacemaker. The terms CRT-P (pacemaker) or CRT-D (defibrillator) are also used, depending on whether the device is a pacemaker alone or also has a defibrillator function.

\section{NYHA}

The New York Heart Association (NYHA) Functional Classification is the most widely used classification system for severity of cardiac weakness:

I: No symptoms

II: Symptoms with high levels of activity

III: Symptoms with low levels of activity

IV: Symptoms at rest 
long time. Guidelines require ICD deactivation to be arranged by qualified staff following adequate discussion with the patient and in consultation with the cardiologist or electrophysiologist treating the patient $(6,7)$. When analyzing treatment aims, incorporating clinical ethical consultation can contribute to a decision that is medically rational, ethically justifiable, and acceptable to the social milieu $(23,24)$. During this discussion, the physician is able to explain that ICD deactivation may be optimal treatment that protects a patient from shock therapy that is no longer medically beneficial. An ICD should not be deactivated by placing a magnet on it except as an absolute last resort (25).

\section{KEY MESSAGES}

- An implantable cardioverter-defibrillator (ICD) cannot prevent death from e.g. heart failure or malignant diseases.

- Approximately $30 \%$ of patients with ICDs receive shock therapy while moribund. While this may be technically correct, there is no longer any medical indication for it.

- ICD shock therapy while a patient is moribund causes major stress for patients, their relatives, and nursing staff.

- A physician treating a patient fitted with an ICD should have an open discussion with the patient, well ahead of time, of the possibilities and limitations of ICD treatment.

- ICDs should preferably be deactivated by specialized staff.

- Close cooperation between cardiologists, geriatricians, palliative care physicians, and medical ethics professionals on a local/regional basis is desirable.

\section{Conflict of interest statement}

Prof. Pfeiffer formerly worked as a consultant for Boston Scientific. He has received reimbursement of conference fees/continuing education costs and travel expenses from St. Jude Medical, ELA Medical, and Boston Scientific. He has received monies paid into a third-party account from St. Jude Medical, ELA Medical, Boston Scientific, and Biotronic.

The other authors declare that no conflict of interest exists.

Manuscript received on 11 July 2011, revised version accepted on 24 January 2012.

Translated from the original German by Caroline Devitt, MA.

\section{REFERENCES}

1. Myerburg RJ, Reddy V, Castellanos A: Indications for implantable cardioverter-defibrillators based on evidence and judgement. J Am Coll Cardiol 2009; 54: 747-63.

2. Epstein AE, DiMarco JP, Ellenbogen KA, Estes NA 3rd, Freedman RA, Gettes LS, et al.: ACC/AHA/HRS 2008 guidelines for devicebased therapy of cardiac rhythm abnormalities. J Am Coll Cardiol 2008; 51: e1-e62
3. Camm AJ, Nisam S: European utilization of the implantable defibrillator: has 10 years changed the "enigma"? Europace 2010; 12: 1063-9.

4. Gadler F: Svenska ICD- och Pacemakerregistret. www.pace makerregistret.se

5. Fromme EK, Lugliani Stewart T, Jeppesen M, Tolle SW: Adverse experiences with implantable defibrillators in Oregon Hospices. Am Hosp Hosp Palliat Care 2011; 28: 304-9.

6. Padeletti L, Arnar DO, Boncinelli L, et al.: European Heart Rhythm Association expert consensus statement on the management of cardiovascular electronic devices in patients nearing end of life or requesting withdrawal of therapy. Europace 2010; 12: 1480-9.

7. Lampert R, Hayes DL, Annas GJ, et al.: Heart Rhythm Society expert consensus statement on the management of cardiovascular electronic devices (CIEDs) in patients nearing end of life or requesting withdrawal of therapy. Heart Rhythm 2010; 7 : 1008-26.

8. Thibodeau JB, Pillarisetti J, Khumri TM, Jones PG, Main ML: Mortality rates and clinical predictors of reduced survival after cardioverter defibrillator implantation. Am J Cardiol 2008; 101: $861-4$.

9. Vidal B, Delgado V, Mont L, et al.: Decreased likelihood of response to cardiac resynchronization in patients with severe heart failure. Eur J Heart Fail 2010; 12: 283-7.

10. Paul, NW: Diagnose und Prognose. In: Schulz S, Steigleder K, Fangerau H, Paul NW (eds.): Geschichte, Theorie und Ethik der Medizin: Eine Einführung. Frankfurt/M: Suhrkamp 2006; $143-52$.

11. England R, England T, Coggon J: The ethical and legal implications of deactivating an implantable cardioverter-defibrillator in a patient with terminal cancer. J Med Ethics 2007; 33: 538-40.

12. Sulmasy DP: Within you/without you: biotechnology, ontology, and ethics. J Gen Intern Med 2007; 23 (suppl 1): 69-72.

13. Zellner RA, Aulisio MP, Lewis WR: Should implantable cardioverter-defibrillators and permanent pacemakers in patients with terminal illness be deactivated? Deactivating permanent pacemaker in patients with terminal illness. Patient autonomy is paramount. Circ Arrhythmia Electrophysiol 2009; 2: 340-4.

14. Kay GN, Bittner GT: Should implantable cardioverter-defibrillators and permanent pacemakers in patients with terminal illness be deactivated? Deactivating implantable cardioverter-defibrillators and permanent pacemakers in patients with terminal illness. An ethical distinction. Circ Arrhythmia Electrophysiol 2009; 2: 336-9.

15. Wu EB: The ethics of implantable devices. J Med Ethics 2007; 33: $532-3$

16. Facciorusso A, Stanislao M, Fanelli M, Valori VM, Valle G: Ethical issues on defibrillator deactivation in end-of-life patients. J Cardiovasc Med 2011; 12: 498-500.

17. Goldstein NE, Mehta D, Siddiqui S, et al.: "That's like an act of suicide": patients attitudes towards deactivation of implantable defibrillators. J Gen Intern Med 2008; 23 (suppl 1): 7-12.

18. Goldstein NE, Mehta D, Teitelbaum E, Bradley EH, Morrison RS: "It's like crossing a bridge" Complexities preventing physicians from discussing deactivation of implantable defibrillator at the end of life. J Gen Intern Med 2007; 23 (suppl 1): 2-6.

19. Goldstein NE, Bradley E, Zeidman J, Mehta D, Morrison RS: Barriers to conversations about deactivation of implantable defibrillators in seriously ill patients. J Am Coll Cardiol 2009; 54: $371-3$.

20. Stewart GC, Weintraub JR, Semigran MJ, et al.: Patient expectations from implantable defibrillators to prevent death in heart failure. J Card Fail 2010; 16: 106-13.

21. Kelley AS, Reid MC, Miller DH, Fins JJ, Lachs MS: Implantable cardioverter-defibrillator deactivation at the end of life: a physician survey. Am Heart J 2009; 157: 702-8. 
22. Sherazi S, Daubert JP, Block RC, et al.: Physician's preferences and attitudes about end-of-life care in patients with an implantable cardioverter-defibrillator. Mayo Clin Proc 2008; 83: 1139-41.

23. Paul NW: Klinische Ethikberatung: Therapieziele, Patientenwille und Entscheidungsprobleme in der modernen Medizin. In: Junginger T, Perneczky A, VAHL CF, Werner C (eds.): Grenzsituationen der Intensivmedizin: Entscheidungsgrundlagen. Heidelberg: Springer 2008; 207-17.

24. Paul NW: Clinical Ethics Counseling: Therapeutic Goals, the Patient's Will and Decision-making Problems in Modern Medicine. Formosan Journal of Medical Humanities 2010; 11: 19-36.

25. Beets MT, Forringer E: Urgent implantable cardioverter defibrillator deactivation by unconventional means. J Pain Symptom Manage 2011; 42: 941-5.

Corresponding author

Prof. Dr. med. Jörg Carlsson

Department of Internal Medicine

Section of Cardiology

Kalmar County Hospital

S-391 85 Kalmar, Sweden

jorg.carlsson@Itkalmar.se

For eReferences please refer to:

www.aerzteblatt-international.de/ref3312 


\title{
REVIEW ARTICLE
}

\section{The Deactivation of Implantable Cardioverter-Defibrillators}

\author{
Medical, Ethical, Practical, and Legal Considerations
}

Jörg Carlsson, Norbert W. Paul, Matthias Dann, Jörg Neuzner, Dietrich Pfeiffer

\section{eReferences}

e1. Trappe HJ, Gummert J: Current pacemaker and defibrillator therapy. Dtsch Arztebl Int 2011; 108(21): 372-80.

e2. Nambisan V, Chao D: Dying and defibrillation: a shocking experience. Palliat Med 2004; 18: 482-3.

e3. Rizzieri AG, Verheijde JL, Rady MY, McGregor JL: Ethical challenges with the left ventricular assist device as a destination therapy. Philos Ethics Humanit Med 2008; 3: 20.

e4. Lindblad A, Juth N, Fürst CJ, Lynöe N: When enough is enough; terminating life-sustaining treatment at the patient's request: a survey of attitudes among Swedish physicians and the general public. J Med Ethics 2010; 36: 284-9.

e5. Kramer DB, Kesselheim AS, Salberg L, Brock DW, Maisel WH: Ethical and legal views regarding deactivation of cardiac implantable electrical devices in patients with hypertrophic cardiomyopathy. Am J Cardiol 2011; 107: 1071-5.

e6. Morrison LJ, Calvin AO, Nora H, Porter Storey C Jr.: Managing cardiac devices near the end of life: a survey of hospice and palliative care providers. Am J Hosp Palliat Care 2010; 27: 545-51.

e7. Kramer DB, Kesselheim AS, Brock DW, Maisel WH: Ethical and legal views of physicians regarding deactivation of cardiac implantable electrical devices: a quantitative assessment. Heart Rhythm 2010; 7: 1537-42.

e8. Marinskis G, van Erven L, HER Scientific Initiatives Committee: Deactivation of implanted cardioverter-defibrillators at the end of life: results of the EHRA survey. Europace 2010; 12: 1176-7.

e9. Rady MY, Verheijde JL: End-of-life discontinuation of destination therapy with cardiac and ventilatory support medical devices: physician-assisted death or allowing the patient to die? BMC Medical Ethics 2010; 11: 15. e10. Dev S, Galanos AN: Complexities of defibrillator deactivation. Ann Intern Med 2010; 153: 133-4.

e11. Mueller PS, Swetz KM, Freeman MR, Carter KA, Crowley ME, Severson CJ, Park SJ, Sulmasy DP: Ethical analysis of withdrawing ventricular assist device support. Mayo Clin Proc 2010; 85: 791-7.

e12. Goldstein NE, Lampert R, Bradley E, Lynn J, Krumholz HM: Management of implantable cardioverter defibrillators in end-of-life care. Ann Intern Med 2004; 141: 835-8.

e13. Berger JT: The ethics of deactivating implanted cardioverter defibrillators. Ann Intern Med 2005; 142: 631-4.

e14. Oorschot B, Simon A: Aktive, passive oder indirekte Sterbehilfe? Über subjektive Definitionen und Klassifikationen von Ärzten und Richtern in Entscheidungssituationen am Lebensende. Psychologie \& Gesellschaftskritik 2008; 32: 39-53.

e15. Kapa S, Mueller PS, Hayes DL, Asirvatham SJ: Perspectives on withdrawing pacemaker and implantable cardioverter-defibrillator therapies at the end of life: results of a survey of medical and legal professionals and patients. Mayo Clin Proc 2010; 85: 981-90.

e16. Mueller PS, Hook C, Hayes DL: Ethical analysis of withdrawal of pacemaker or implantable cardioverter-defibrillator support and the end of life. Mayo Clin Proc 2003; 78: 959-63.

e17. Raphael C, Kanagaratnam P, Francis DP: Further barriers to conversations about deactivation of implantable cardioverterdefibrillators. J Am Coll Cardiol 2010; 55: 701-2.

e18. http://juris.bundesgerichtshof.de/cgi-bin/rechtsprechung/ document.py?Gericht=bgh\&Art=en\&Datum =2010-6\&Seite= $1 \& n r=52999 \&$ pos $=49 \&$ \&nz $=313$ 